\title{
Chlorine poisoning caused by improper mixing of household disinfectants during the COVID-19 pandemic
}

\section{Lin Guodong ( $\sim 619323963 @ q q . c o m$ )}

PLA General Hospital of Southern Theatre Command: People's Liberation Army General Hospital of Southern Theatre Command Wu Jieyi

PLA General Hospital of Southern Theatre Command: People's Liberation Army General Hospital of Southern Theatre Command

\section{Peng Xiaobo}

General Hospital of People's Liberation Army: Chinese PLA General Hospital

\section{Lu xiaoxia}

General Hospital of People's Liberation Army: Chinese PLA General Hospital

\section{Liu zhongying}

General Hospital of People's Liberation Army: Chinese PLA General Hospital

\section{Pan Zhiguo}

PLA General Hospital of Southern Theatre Command: People's Liberation Army General Hospital of Southern Theatre Command

\section{Qiu zewu}

PLA General Hospital of Southern Theatre Command: People's Liberation Army General Hospital of Southern Theatre Command

\section{Dong Jianguang}

PLA General Hospital of Southern Theatre Command: People's Liberation Army General Hospital of Southern Theatre Command

\section{Research}

Keywords: hypochlorite bleach, acidic cleaning agents, chlorine poisoning, toxic lung injury, household disinfectant

Posted Date: November 19th, 2021

DOI: https://doi.org/10.21203/rs.3.rs-1081660/v1

License: (1) This work is licensed under a Creative Commons Attribution 4.0 International License. Read Full License 


\section{Abstract \\ Background}

During the coronavirus disease 2019 (COVID-19) pandemic, many people have abused and misused disinfectants, leading to many poisoning incidents. However, there are few clinical case reports of poisoning caused by mixed household disinfectants. This study summarized the clinical characteristics and treatment effects of chlorine poisoning caused by improper mixing of hypochlorite bleach with acidic cleaning agents to improve the understanding of the disease.

\section{Methods}

We retrospectively analyzed the basic data, clinical symptoms, treatment methods, imaging, and other clinical data of seven patients with chlorine poisoning, caused by an improper mixture of hypochlorite bleach and acidic cleaning agents, who were admitted to the National Army Poisoning Treatment Center.

\section{Results}

The seven patients (three men and four women) had an average age of 48.8 years (18-67 years). The average poisoning time (time from exposure to poison to treatment) was $57 \mathrm{~h}(4-240 \mathrm{~h}$ ). All seven patients were involved in cleaning bathrooms during the COVID19 pandemic. Chest computed tomography scans showed bilateral lung effusions or inflammatory changes in five patients and no obvious exudation or inflammatory changes in two. The partial pressure of oxygen decreased in six patients, and respiratory failure occurred in one. Five patients had different degrees of increase in white blood cell count. For treatment, humidified oxygen therapy, non-invasive mechanical ventilation, intravenous corticosteroids, inhaled hormone, bronchial spasmolytics, antibiotics, and other symptomatic and supportive treatments were provided. The average length of hospital stay was 7 days (4-9 days). All seven patients recovered and were discharged.

\section{Conclusions}

Improper mixing of house disinfectants during the COVID-19 pandemic may cause damage to the respiratory system due to chlorine poisoning. Corticosteroids may improve lung exudation in severe cases. Additionally, symptomatic supportive treatment should be performed early.

\section{Background}

There are many types of household disinfection products, and the incidence of poisoning related to these products, caused by misuse and accidents, remains high [1-4]. Among them, inhalation-induced poisoning accounts for a large proportion of cases and often causes serious injuries [3, 4]. In China, 84 disinfectants (with sodium hypochlorite as the main component) and toilet cleaner (diluted hydrochloric acid) are widely used in households, and there are many poisoning incidents involving these products [4]. The use of household disinfectants increased significantly during the coronavirus disease 2019 (COVID-19) pandemic [5-7]. It is common for people to use disinfectants incorrectly [6]. Furthermore, some people think that household disinfectants can eliminate the novel coronavirus, and household disinfection is inappropriately conducted $[2,7,8]$. Household disinfectants may cause toxic reactions and produce toxic gases, including chlorine [2-4, 9]. Chlorine exposure is usually caused by accidental release of chlorine vapor from swimming pools, improper mixing of hypochlorite bleach and acid cleaners, school chemical experiments, and industrial or chemical transportation accidents [9-13]. Due to its high toxicity and common availability, chlorine gas has also been used in terrorist attacks and chemical warfare agents $[11,12]$. There are a few clinical case reports on acute chlorine inhalation poisoning caused by improper mixing of household disinfectants and toilet cleaners [3]. Yet, clinicians lack a deep understanding of the possible clinical manifestations and prognosis of such patients. Here, we summarized the clinical data of seven patients admitted to our center during the COVID-19 pandemic with acute chlorine inhalation poisoning caused by improper mixing of disinfectants and toilet cleaners. The summary could help improve a clinician's ability to treat future cases. 


\section{Methods}

\section{Study design and population}

We collected and retrospectively analyzed the clinical data, diagnosis, and treatment of seven patients with acute chlorine inhalation poisoning caused by improper mixing of disinfectants and toilet cleaners who were admitted to the National Army Poisoning Treatment Center from March 2020 to September 2021. All patients had a clear history of inhaling chlorine gas, an irritant, produced by improper mixing of toilet cleaners and any of the 84 disinfectants widely used in Chinese households. The collected data included the patients' baseline data: sex, age, underlying disease, poisoning time, and cause of poisoning; clinical manifestations: main symptoms, related laboratory tests, and imaging data; and diagnosis and treatment process: treatment methods, hospitalization days, prognosis, and follow-up prognosis. All patients provided informed consent, and the retrospective study design was approved by the appropriate ethics review board of our hospital.

\section{Statistical analyses}

Descriptive statistics were used to summarize the data; results are reported as the mean (minimum-maximum). No imputation was performed for missing data. Analysis was performed using Stata 15.1 software.

\section{Results}

\section{Baseline characteristics}

The patients included three males and four females, with an average age of 48.8 years (18-67 years). All patients confirmed that they mixed two kinds of household disinfection products to clean household items or toilets and saw the production of yellow-green gas; the diagnosis of poisoning due to chlorine gas inhalation was clear. The average poisoning time (time from exposure to poison to treatment) was $57 \mathrm{~h}(4-240 \mathrm{~h})$. All patients' poisoning occurred while disinfecting a room during the COVID-19 pandemic. The patients' data are summarized in Table 1. 
Table 1

Baseline characteristics at admission and major treatments

\begin{tabular}{|c|c|c|c|c|c|c|c|c|}
\hline & $\begin{array}{l}\text { Age, } \\
\text { (y) }\end{array}$ & Sex & Comorbidities & Initial symptoms & $\begin{array}{l}\text { Admission } \\
\text { time }\end{array}$ & $\begin{array}{l}\mathrm{PaO2/} \\
\mathrm{FiO2}\end{array}$ & $\begin{array}{l}\text { Computed } \\
\text { Tomography }\end{array}$ & Major treatments \\
\hline 1 & 60 & $\mathrm{~F}$ & $\begin{array}{l}\text { Hypertension, } \\
\text { hyperthyroidism }\end{array}$ & $\begin{array}{l}\text { Breathlessness, } \\
\text { difficulty } \\
\text { breathing, } \\
\text { headache, } \\
\text { dizziness }\end{array}$ & $3 \mathrm{~h}$ & 318.10 & $\begin{array}{l}\text { Bilateral lung } \\
\text { effusions }\end{array}$ & $\begin{array}{l}\text { Humidified oxygen; } \\
\text { methylprednisolone( } 80 \mathrm{mg} \\
\text { for } 3 \mathrm{~d} \text {, } 40 \mathrm{mg} \text { for } 3 \mathrm{~d}) ; \\
\text { inhalated budesonide and } \\
\text { bromhexine; cefmetazole } \\
\text { anti-infection; }\end{array}$ \\
\hline 2 & 61 & M & None & Breathlessness & $10 d$ & 372.38 & $\begin{array}{l}\text { Bilateral } \\
\text { interstitial } \\
\text { exudations }\end{array}$ & $\begin{array}{l}\text { Humidified oxygen; } \\
\text { methylprednisolone( } 80 \mathrm{mg} \\
\text { for } 3 \mathrm{~d} \text {, } 40 \mathrm{mg} \text { for } 3 \mathrm{~d}) \text {; } \\
\text { inhalated budesonide and } \\
\text { bromhexine; azithromycin } \\
\text { anti-infection; }\end{array}$ \\
\hline 3 & 60 & $\mathrm{~F}$ & None & $\begin{array}{l}\text { Fatigue, } \\
\text { breathlessness, } \\
\text { coughing, } \\
\text { choking of the } \\
\text { pharynx, } \\
\text { dizziness, } \\
\text { headache, } \\
\text { transient } \\
\text { unconsciousness, } \\
\text { urinary } \\
\text { incontinence }\end{array}$ & $24 h$ & 215.52 & $\begin{array}{l}\text { Bilateral lung } \\
\text { effusions }\end{array}$ & $\begin{array}{l}\text { Humidified oxygen; } \\
\text { methylprednisolone } \\
\text { ( } 80 \mathrm{mg} \text { for } 3 \mathrm{~d}, 40 \mathrm{mg} \text { for } 3 \\
\text { d); inhalated budesonide } \\
\text { and bromhexine; } \\
\text { cefmetazole anti- } \\
\text { infection; }\end{array}$ \\
\hline 4 & 18 & $\mathrm{~F}$ & None & $\begin{array}{l}\text { Dizziness, } \\
\text { coughing, } \\
\text { nausea, vomiting }\end{array}$ & $6 \mathrm{~h}$ & 396.19 & $\begin{array}{l}\text { Striped } \\
\text { shadow under } \\
\text { the pleura of } \\
\text { the right lung }\end{array}$ & $\begin{array}{l}\text { (pre-hospital) } \\
\text { Dexamethasone(10mg); } \\
\text { humidified oxygen; } \\
\text { mthylprednisolone(40mg } \\
\text { for } 3 \mathrm{~d}) \text {; }\end{array}$ \\
\hline 5 & 56 & $M$ & $\begin{array}{l}\text { Smoking } \\
\text { history for } 30 \\
\text { years }\end{array}$ & $\begin{array}{l}\text { Chest tightness, } \\
\text { breathlessness }\end{array}$ & $12 \mathrm{~h}$ & 342.86 & $\begin{array}{l}\text { Bilateral lung } \\
\text { emphysema } \\
\text { and bullae }\end{array}$ & $\begin{array}{l}\text { Humidified oxygen; } \\
\text { inhalated budesonide and } \\
\text { bromhexine; } \\
\text { methylprednisolone( } 80 \mathrm{mg} \\
\text { for } 3 \mathrm{~d}, 40 \mathrm{mg} 3 \mathrm{~d}) \text {; } \\
\text { moxifloxacin anti- } \\
\text { infection; }\end{array}$ \\
\hline 6 & 20 & $\mathrm{M}$ & $\begin{array}{l}\text { Smoking } \\
\text { history for } 2 \\
\text { years }\end{array}$ & $\begin{array}{l}\text { Chest tightness, } \\
\text { cough, choking in } \\
\text { the pharynx, } \\
\text { breathlessness, } \\
\text { difficulty } \\
\text { breathing }\end{array}$ & $17 \mathrm{~h}$ & 198.62 & $\begin{array}{l}\text { Bilateral lung } \\
\text { effusions }\end{array}$ & $\begin{array}{l}\text { Non-invasive mechanical } \\
\text { ventilation; } \\
\text { methylprednisolone } \\
\text { ( } 80 \mathrm{mg} \text { for } 5 \mathrm{~d}, 40 \mathrm{mg} \text { for } 2 \\
\text { d); inhalated budesonide } \\
\text { and bromhexine; } \\
\text { Moxifloxacin anti- } \\
\text { infection; }\end{array}$ \\
\hline 7 & 67 & $\mathrm{~F}$ & $\begin{array}{l}\text { Hypertension } \\
\text { history for } 24 \\
\text { years }\end{array}$ & $\begin{array}{l}\text { Coughing, } \\
\text { breathlessness }\end{array}$ & $4 d$ & 210.34 & $\begin{array}{l}\text { Increased } \\
\text { texture of } \\
\text { blood vessels } \\
\text { in bilateral } \\
\text { Lung and } \\
\text { multiple } \\
\text { patchy change } \\
\text { under the } \\
\text { pleura;bilateral } \\
\text { pneumonia } \\
\text { changes; }\end{array}$ & $\begin{array}{l}\text { Methylprednisolone( } 80 \mathrm{mg} \\
\text { for } 3 \mathrm{~d}, 40 \mathrm{mg} \text { for } 3 \mathrm{~d}) \text {; } \\
\text { inhalated budesonide and } \\
\text { bromhexine; moxifloxacin } \\
\text { anti-infection; }\end{array}$ \\
\hline
\end{tabular}

\section{Clinical and clinicopathological symptoms}

The clinical manifestations and severity of poisoning due to intoxication time, absorption, age, and individual physiques differed the among patients included in this study. Among the seven patients, six had mild symptoms and one had severe symptoms. 
Additionally, six had breathlessness, two had dyspnea, three had a headache, three had dizziness, three had a cough, two had pharyngeal discomfort, one had fatigue, one had nausea, and one had vomiting symptoms. One patient developed transient unconsciousness (recovered consciousness in approximately $1 \mathrm{~min}$ ) and urinary incontinence. The patients' symptoms are shown in Table 1. The laboratory test results on admission showed an average white blood cell count of $13.61 \times 10^{9} / \mathrm{L}\left(3.83-19.05 \times 10^{9} / \mathrm{L}\right)$. The average oxygen partial pressure was $68.17 \mathrm{mmHg}(57.6-83.2 \mathrm{mmHg})$, and the average oxygenation index was $293.43 \mathrm{mmHg}$ (198.62-396.19 mmHg). Among the patients, three had toxic lung injury (oxygenation index $<300 \mathrm{mmHg}$ ), one had an oxygenation index $<200 \mathrm{mmHg}$, six had hypoxemia, one had type I respiratory failure, and five had chest computed tomography (CT) scans showing bilateral lung effusions or inflammatory changes. Chest CT scans of two of the patients showed no obvious exudation or inflammatory changes. The chest CT image of the heaviest patient (patient 6 in Table 1) is shown in Figure 1. Supplementary Material 1 shows the chest CT images of the other patients.

\section{Treatment, prognosis, and follow-up}

Six of the patients received humidified oxygen, and one patient was treated with non-invasive mechanical ventilation. In addition to anti-inflammatory glucocorticoids (including intravenous methylprednisolone and inhaled hormone) (see Table 1 for specific dosages), to relieve bronchospasm and reduce phlegm, antioxidants and antibiotics were used to maintain the acid-base electrolyte balance and prevent bacterial infection, respectively. After treatment, all the patients' conditions improved, and repeat chest CT scans showed significant improvement (see Figure 1 and supplementary materials). The average length of hospital stay was 7 days (4-9 days). All patients recovered and were discharged, and no symptom recurrence was observed after follow-up.

\section{Discussion}

The cases we reported described chlorine poisoning caused by improper mixing of toilet cleaners and any of the 84 disinfectants commonly used in Chinese households during the COVID-19 pandemic. The effective ingredients of these products include diluted hydrochloric acid and sodium hypochlorite. Mixing both these solutions causes a chemical reaction that produces chlorine gas. Among the seven patients with chlorine poisoning, one had severe symptoms. The chest CT scan showed significant bilateral lung effusion, and the patient's blood gas analysis indicated type I respiratory failure. However, after active treatment, the condition of all patients improved significantly. This highlights the importance of early detection, diagnosis, and treatment and presents our valuable experience in treating patients with chlorine poisoning.

Chlorine is a toxic and irritating gas $[9,14]$. Due to the different concentrations, intoxication times, and individual sensitivities of the human body, acute chlorine gas inhalation can cause varying degrees of damage to the human body and even be life-threatening [11, 15-17]. After inhalation through the respiratory tract, the chlorine gas reacts with moisture on the mucosal surface of the respiratory tract to generate hypochlorous and hydrochloric acid $[11,15]$. Hypochlorous acid can be decomposed into hydrochloric acid and new ecological oxygen, causing local irritation and corrosion [4]. As chlorine can combine with reactive oxygen species and other airway fluid components to form a variety of highly active oxidants, the airway epithelium may immediately undergo direct oxidative damage $[11,15]$. Additionally, the migration and activation of inflammatory cells, such as neutrophils, in the airway epithelium and the subsequent release of oxidants and proteolytic enzymes may cause further damage to the epithelium [15]. Therefore, chlorine poisoning can cause bronchospasm and bronchitis, and in severe cases, it can cause pulmonary edema and may be accompanied by damage to other organ systems, such as the cardiopulmonary and nervous systems $[9,18,19]$. Acute chlorine poisoning is characterized by acute respiratory system damage [17]. All seven patients in our study had respiratory symptoms, such as wheezing, dyspnea, and pharyngeal discomfort. Imaging indicated varying degrees of lung injury. Most of the patients had different degrees of increase in white blood cell counts and high-sensitivity C-reactive protein levels, suggesting an acute inflammatory response. The direct interaction of chlorine and acute inflammatory response may lead to acute toxic lung injury and its complications [15]. One patient had transient unconsciousness, suggesting that chlorine may have a toxic effect on the human nervous system[19], which is consistent with what is reported in the literature [19].

Current treatment measures in response to acute chlorine inhalation poisoning, which mainly causes toxic lung injury and systemic inflammation, include humidified oxygen therapy, use of corticosteroids (intravenous and inhaled), airway antispasmodic drugs, antioxidants, and inhaled sodium bicarbonate $[9,17]$. Recent studies suggest TRPV4 inhibitors, dimethylthiourea, and rolipram as therapeutic options, although these have not been clinically used $[9,17]$. Furthermore, there are doubts about the efficacy of glucocorticoids among these treatment measures, and currently, extensive studies to verify the findings are scarce [9]. Our study used

Page 5/8 
the treatment strategy of intravenous methylprednisolone combined with inhaled hormone and found that the effect of this treatment on heavier patients was significant. Corticosteroid therapy can significantly reduce inflammatory exudation caused by chlorine gas, and our study presents clinical experience on the use of corticosteroids for the treatment of chlorine poisoning [9]. Current treatment measures for hypoxemia and respiratory failure caused by chlorine poisoning include humidified oxygen therapy, non-invasive mechanical ventilation, invasive mechanical ventilation, and extracorporeal membrane oxygenation therapy $[9,17,20]$. In this study, six patients with hypoxemia received oxygen therapy and one critically ill patient received non-invasive mechanical ventilation; all patients' breathing conditions significantly improved. None of the patients received invasive mechanical ventilation. Therefore, with the treatment experience of our seven patients, we conclude that the treatment should be based on the principles of inflammation control; antioxidant therapy; protection of lung function; prevention and treatment of pulmonary edema; protection of the heart, liver, brain, kidney, and other essential organ functions; and improvement of oxygen delivery. In terms of treatment, recommended emergency intervention steps include 1) immediately move away from the scene to a place with fresh air, keep the respiratory tract unobstructed, and provide timely and effective oxygen therapy; 2) provide non-invasive mechanical ventilation or even invasive mechanical ventilation when necessary to improve respiratory conditions and increase oxygen delivery; and 3) administer early, adequate, short-term corticosteroid therapy to improve pulmonary edema. In this study, $40-80 \mathrm{mg} /$ day of methylprednisolone was administered for 3-7 days. Other treatments included antispasmodic and anti-asthmatic symptomatic treatment, including supporting essential organ functions, nutritional support, maintenance of water and electrolytes, and acid-base balance. In principle, it is not recommended to use antibiotics to treat acute chlorine inhalation poisoning, but it was administered to prevent opportunistic bacterial infections. Appropriate antibiotics should be administered to treat infections timeously [17]. To prevent infection, we administered antibiotics to all patients in this study. However, the advantages and disadvantages of using corticosteroids and antibiotics to prevent infection in acute chlorine inhalation poisoning should be further investigated [17]. Additionally, some researchers have attempted to atomize bicarbonate to treat the acidic environment of the airways and lungs caused by chlorine poisoning, but its dosage is uncontrollable and the benefits from the perspective of lung physiology are unclear [17]. Furthermore, new treatment methods (including TRPV4 antagonists, dimethylthiourea, and rolipram) are still experimental.

\section{Conclusions}

Overall, there are no specific antidotes and effective treatment measures for acute chlorine inhalation poisoning, and comprehensive supportive treatment is the primary treatment method. Additionally, corticosteroids may improve lung exudation. Therefore, it is crucial to understand and prevent acute chlorine inhalation poisoning. It has been very important to use household disinfectants correctly to prevent chlorine inhalation poisoning during the COVID-19 pandemic. Hydrochloric acid and sodium hypochlorite disinfectant products, such as commonly used disinfectants and toilet cleaners, should not be mixed. Should chlorine inhalation poisoning occur, timely ventilation and hospital medical treatment are required.

\section{Abbreviations}

CT: computed tomography; COVID-19: coronavirus disease 2019

\section{Declarations}

\section{Competing interests}

The authors declare that they have no competing interests.

\section{Consent for publication}

Written informed consent for publication of the clinical details and clinical images was obtained from the patient.

\section{Authors' contributions}

Lin Guodong, Tong Huashen, Qiu Zewu and Dong Jianguang conceived the study, designed the trial, and obtained research funding. Peng Xiaobo, Lu Xiaoxia and Liu Zhongying supervised data collection and managed the data, including quality control. Qiu Zewu and Dong Jianguang provided statistical advice on study design and analyzed the data. Lin Guodong and Wu Jieyi drafted the 
manuscript, and all authors contributed substantially to its revision. Tong Huashen, Qiu Zewu and Dong Jianguang take responsibility for the paper as a whole.

\section{References}

1. Ha Y, Kim Y, Song E, Yoo HJ, Kwon JH. Development of a personal passive air sampler for estimating exposure to effective chlorine while using chlorine-based disinfectants. Indoor air. 2021;31(2):557-65.

2. Quirce S, Barranco P. Cleaning agents and asthma. Journal of investigational allergology \& clinical immunology. 2010;20(7):54250 .

3. McKenzie LB, Ahir N, Stolz U, Nelson NG. Household cleaning product-related injuries treated in US emergency departments in 1990-2006. Pediatrics. 2010;126(3):509-16.

4. Racioppi F, Daskaleros PA, Besbelli N, Borges A, Deraemaeker C, Magalini SI, et al. Household bleaches based on sodium hypochlorite: review of acute toxicology and poison control center experience. Food and chemical toxicology : an international journal published for the British Industrial Biological Research Association. 1994;32(9):845-61.

5. Yasseen lii A, Weiss D, Remer S, Dobbin N, MacNeill M, Bogeljic B, et al. Increases in exposure calls related to selected cleaners and disinfectants at the onset of the COVID-19 pandemic: data from Canadian poison centres. Health promotion and chronic disease prevention in Canada : research, policy and practice. 2021;41(1):25-9.

6. Gharpure R, Miller GF, Hunter CM, Schnall AH, Kunz J, Garcia-Williams AG. Safe Use and Storage of Cleaners, Disinfectants, and Hand Sanitizers: Knowledge, Attitudes, and Practices among U.S. Adults during the COVID-19 Pandemic, May 2020. The American journal of tropical medicine and hygiene. 2020.

7. Gharpure R, Hunter CM, Schnall AH, Barrett CE, Kirby AE, Kunz J, et al. Knowledge and Practices Regarding Safe Household Cleaning and Disinfection for COVID-19 Prevention - United States, May 2020. MMWR Morbidity and mortality weekly report. 2020;69(23):705-9.

8. Chang A, Schnall AH, Law R, Bronstein AC, Marraffa JM, Spiller HA, et al. Cleaning and Disinfectant Chemical Exposures and Temporal Associations with COVID-19 - National Poison Data System, United States, January 1, 2020-March 31, 2020. MMWR Morbidity and mortality weekly report. 2020;69(16):496-8.

9. Huynh Tuong A, Despreaux T, Loeb T, Salomon J, Megarbane B, Descatha A. Emergency management of chlorine gas exposure - a systematic review. Clinical toxicology. 2019;57(2):77-98.

10. Na W, Wang Y, Li A, Zhu X, Xue C, Ye Q. Acute chlorine poisoning caused by an accident at a swimming pool. Toxicology and industrial health. 2021;37(9):513-9.

11. Zellner T, Eyer F. Choking agents and chlorine gas - History, pathophysiology, clinical effects and treatment. Toxicology letters. 2020;320:73-9.

12.Wilken JA, DiMaggio M, Kaufmann M, O'Connor K, Smorodinsky S, Armatas C, et al. Inhalational Chlorine Injuries at Public Aquatic Venues - California, 2008-2015. MMWR Morbidity and mortality weekly report. 2017;66(19):498-501.

13. Cevik Y, Onay M, Akmaz I, Sezigen S. Mass casualties from acute inhalation of chlorine gas. Southern medical journal. 2009;102(12):1209-13.

14. Akdur O, Durukan P, Ikizceli I, Ozkan S, Avsarogullari L. A rare complication of chlorine gas inhalation: pneumomediastinum. Emergency medicine journal : EMJ. 2006;23(11):e59.

15. Pesonen M, Vahakangas K. Chloropicrin-induced toxicity in the respiratory system. Toxicology letters. 2020;323:10-8.

16. Carpenter A, Cox AT, Marion D, Phillips A, Ewington I. A case of a chlorine inhalation injury in an Ebola treatment unit. Journal of the Royal Army Medical Corps. 2016;162(3):229-31. 
17. Howard C, Ducre B, Burda AM, Kubic A. Management of chlorine gas exposure. Journal of emergency nursing. 2007;33(4):402-4.

18. Carlisle M, Lam A, Svendsen ER, Aggarwal S, Matalon S. Chlorine-induced cardiopulmonary injury. Annals of the New York Academy of Sciences. 2016;1374(1):159-67.

19. Kilburn KH. Brain but not lung functions impaired after a chlorine incident. Industrial health. 2003;41(4):299-305.

20. Matos AM, Oliveira RR, Lippi MM, Takatani RR, Oliveira WF. Use of noninvasive ventilation in severe acute respiratory distress syndrome due to accidental chlorine inhalation: a case report. Revista Brasileira de terapia intensiva. 2017;29(1):105-10.

\section{Figures}

\section{Figure 1}

Chest CT image of the heaviest patient.

\section{Supplementary Files}

This is a list of supplementary files associated with this preprint. Click to download.

- SupplementaryMaterial1.docx 